\title{
LA CONSTRUCCIÓN CULTURAL DEL TRIBUTO (EN DIÁLOGO INTEGRATIVISTA TRIALISTA)
}

DORA ESTHER AYALA ROJAS

FACULTAD DE DERECHO, CIENCIAS SOCIALES Y POLÍTICAS UNIVERSIDAD NACIONAL DEL NORDESTE - UNNE ARGENTINA

"La vida solo puede ser comprendida mirando hacia atrás, pero ha de ser vivida mirando hacia adelante". Sören Kierkegaard. 


\title{
RESUMEN
}

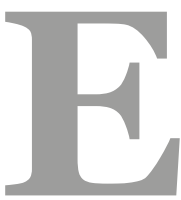

l tributo, en su significado más generalizado, es un recurso público por el que el Estado obtiene ingresos que destina al cumplimiento de sus fines. Sin embargo, este concepto no siempre se interpretó del mismo modo, sino que se fue transformando a medida que las funciones estatales se hicieron cada vez mayores y sus intervenciones se extendieron más allá de las funciones consideradas básicas. En ese trayecto, el tributo fue el motivo principal - y a veces el único - desencadenante de importantes movimientos sociales y políticos en los que contribuyó a poner en evidencia al momento de diseñar la política estatal, la tensión permanente entre el poder soberano y la libertad individual.

El debate sobre su legitimidad gira de manera más o menos explícita, alrededor de la necesidad que quienes lo soporten, sean los que más tienen/obtienen; y por lo tanto asumen el deber de contribuir en mayor medida al sostenimiento del Estado y a la distribución de la renta entre los miembros de la comunidad.

Consideramos que el tributo es una respuesta cultural para sostener al Estado en su acepción más amplia de colectividad humana organizada. Para demostrarlo partimos de una visión integrativista, con énfasis en la teoría trialista del mundo jurídico, analizando el fenómeno de la tributación desde los rasgos comunes a todo fenómeno jurídico, esto es, en sus tres dimensiones (social, normativa y valorativa); y las relaciones materiales, temporales y espaciales que integran la complejidad entre el ejercicio de la libertad y el deber de tributar.

Palabras clave: tributos, ingresos, complejidad, integración, cultura.

\begin{abstract}
The tax in its most widespread meaning, is a public resource for which the State obtains incomes that it destines to the fulfillment of its ends. Nevertheless, this concept not always was interpreted in the same way. It was transforming to the extent that the state functions became every time majors and its interventions extended beyond the basic considered functions. During this journey, the tax was the principal motive - and sometimes the only one - trigger of important social and political movements in which it contributed to put in evidence the permanent tension up between the sovereign power and the individual freedom, at the time of designing the state politics.

The debate on its legitimacy turns in a more or less explicit way, about the need that those who bear it, are those that they more have / obtain, and therefore they assume the duty to contribute in greater extent to the support of the State and to the redistribution of the income between the community members.
\end{abstract}


It is considered that the tax is a cultural response to the maintenance of the state in its widest meaning of organized human community. To demonstrate it, it starts from the integrativista conception, with emphasis on the trialista theory of the juridical world, analyzing the taxation phenomenon from the common characteristics to every juridical phenomenon, this is, in its three dimension (social, normative and valorative) and the material, temporary and spatial relations that integrate the complexity between the exercise of the freedom and the duty to pay tax.

Keywords: tax, incomes, complexity, integrate, cultural.

\section{INTRODUCCIÓN. LOS CONTEXTOS}

\subsection{IDEAS BÁSICAS SOBRE EL TRIBUTO}

El tributo en su significado más generalizado, es un recurso público por el que el Estado obtiene ingresos que destina al cumplimiento de sus fines. Sin embargo, este concepto no siempre se interpretó del mismo modo. Se fue transformando a medida que las funciones estatales se hicieron cada vez mayores y sus intervenciones se extendieron más allá de las funciones consideradas básicas. Durante ese trayecto, el tributo fue el motivo principal - y a veces el único - desencadenante de importantes movimientos sociales y políticos en los que contribuyó a poner en evidencia la tensión permanente entre el poder soberano y la libertad individual, a la hora de diseñar la política estatal.

El debate sobre su legitimidad gira de manera más o menos explícita, alrededor de la necesidad que quienes lo soporten, sean los que más tienen/obtienen, y por lo tanto asumen el deber de contribuir en mayor medida al sostenimiento del Estado y a la distribución de la renta entre los miembros de la comunidad.

En realidad, la relación entre el ejercicio de la libertad y el deber de tributar es sumamente compleja. Para dar fundamento a esa legitimidad se ha construido el concepto de capacidad contributiva ${ }^{1}$ o requisito material del hecho imponible (Pérez de Ayala, J., y González García, E., 1994, p. 155) que se explicita como renta, patrimonio y/o consumo gravados.

Consideramos que el tributo es una respuesta cultural al sostenimiento del Estado en su acepción más amplia de colectividad humana organizada. Para demostrarlo partimos de la concepción integrativista de la teoría trialista del mundo jurídico, analizando el fenómeno de la tributación en dos partes: la primera, ubicará las relaciones materiales, temporales y espaciales que integran su complejidad a partir de su identificación conceptual; la segunda, le aplicará los

\footnotetext{
${ }^{1}$ La expresión no fue aceptada pacíficamente. Algunos prefieren la de capacidad económica. Sin embargo, cualquiera sea la postura, se trata de una manifestación de riqueza o de aptitud para concurrir al sostenimiento de los gastos públicos; de ahí la intima conexión entre capacidad contributiva y hecho imponible.
} 
rasgos comunes a todo fenómeno jurídico (dimensión social, normativa y valorativa²).

Históricamente, el concepto de tributo es diferente para las distintas culturas. De su evolución surge que cada comunidad tienen ideas propias, tanto de su importancia como de sus efectos ${ }^{3}$.

Las civilizaciones orientales caracterizadas por un sentimiento fatalista y mágico, marcado por gobiernos absolutos y una profunda influencia religiosa sobre todos los aspectos de la vida, reflejaron esos rasgos en los tributos.

En la India, el Artha Shastra (Libro de la Ciencia de la Riqueza, de Kantilya ${ }^{4}$ ) cuya antigüedad se remonta a 300 años antes de Cristo, expresa que así como los frutos deben ser cosechados del árbol cuando estén maduros, así los recursos deben recaudarse cuando las rentas estén presentes (Ahumada, G., 1969, p. 47). El tributo se relaciona aquí con la ética y el buen obrar. Mucho después (en 1930) la Marcha de la Sal, da al tributo connotaciones socio políticas, al ser utilizada por Gandhi como un motivo de lucha no violenta por la independencia de la India 5 .

En el Antiguo Imperio de Egipto existieron tributos sobre los consumos y las rentas que debían ser soportados por algunas clases sociales: militares, agricultores, artesanos y pastores. Los nobles y sacerdotes estaban eximidos así como los escribas, que eran recaudadores ${ }^{6}$. Además, papiros de ese período dan cuenta de un impuesto en especie - cereales - que debían pagarlo todos; y aquellos que no cultivaban cereales tenían que comprarlos para poder tributar (Gerloff, W., y Neumark, F., 1961, p. 220). El tributo se relaciona así con la estratificación como función social.

Para el pueblo hebreo, los tributos trascendieron lo económico. A la muerte del rey Salomón (974 a C) las tribus se presentaron ante su hijo para solicitar la disminución de los altos impuestos que les cobraba. Ante su negativa, diez de las doce tribus se sublevaron y formaron al norte el Reino de Israel. Al sur quedaron las dos tribus restantes unidas en el pequeño Reino de Judea que con su capital en Jerusalén, constituyeron luego un hito en la historia del Oriente Medio: la fractura de la unidad política del pueblo hebreo trajo consecuencias que hasta hoy persisten sobre toda la región7. El tributo se relaciona con la unidad política de la comunidad hebrea y de Oriente Medio.

Lo que más tarde recibirá el nombre de Civilización Occidental, tuvo inicio en Grecia y se caracterizó por el descubrimiento del hombre como medida de todas las cosas.

En los orígenes de Atenas (siglo XIII a C) el gobierno de los nobles era brutal con el pueblo que vivía agobiado por los impuestos, especialmente aquellos que gravaban la tierra. Las

\footnotetext{
2 Sociológica, normológica y dikelógica, en los términos originales de la Teoría Trialista del Mundo Jurídico.

${ }^{3}$ Para el trialismo, la dimensión temporal del análisis o Historia del derecho, constituye un aspecto esencial en la construcción del objeto jurídico.

${ }^{4}$ Nombre con el que es identificado el autor del Tratado - Chanakia - a quien algunos consideran un pionero economista comparable a Maquiavelo del mundo occidental. La obra refiere a las condiciones que debe reunir un rey virtuoso. Vincula economía y ética. ${ }^{5}$ Mediante el gesto simbólico de recoger del mar un punado de sal, Gandhi alienta a sus compatriotas a violar el monopolio británico sobre la distribución de sal. En razón de ese monopolio, la población debía pagar por el consumo de sal un alto impuesto, análogo al establecido en la Francia del Antiguo Régimen.

${ }^{6}$ La misma función cumplían los sátrapas, en el Imperio Persa (500 a c).

${ }^{7}$ El debilitamiento de la monarquía hebrea por luchas internas, les permitió a sus vecinos - asirios y caldeos - invadir su territorio hasta que finalmente los últimos ocuparon Jerusalén y trasladaron a Babilonia - actual territorio de Irak - a la mayor parte de los judíos, con efectos sociales culturales y religiosos importantes y que hasta hoy se evidencian como conflictos de la región.
} 
leyes elaboradas por Dracón fueron tan severas para quienes no pagaban tributos, que lejos de calmar al pueblo aumentaron los desórdenes. Con la llegada de Solón aquellas irritantes medidas quedaron sin efecto mediante una reforma que determinó la obligación de tributar en relación directa con la fortuna, sistema que Clístenes fortaleció al darles a libertos y colonos extranjeros el derecho de ciudadanía. El tributo aparece esencialmente ligado a la propiedad de la tierra, aunque hubo otros - pero no conflictivos - como la liturgia, destinada a solventar fiestas públicas y otros gastos de lujo y la éisfora, que se utilizaba para afrontar gastos de guerra.

Luego el legado griego pasó a Roma donde se construyó un sistema jurídico y político que dominó el mundo antiguo en una patria común: la gran Roma. Se establecieron tributos para mantener el vasto imperio, algunos extra fiscales ${ }^{8}$, antecedentes a los actuales; y se crearon cargos municipales para velar por los intereses del fisco (el curator) y de los habitantes (el defensor civitatis). El tributo aparece relacionado con el poder de imperio y los derechos ciudadanos.

Durante la Edad Media los tributos estaban asimilados a obligaciones privadas. La fidelidad del vasallo era un signo de servidumbre, no derivaba de un deber universal sino de una contingencia a menudo arbitraria o caprichosa; y siempre particular (Martín, J., 1976, p. 42). Muestra de la reacción contra los abusos fue la sublevación del pueblo de Inglaterra y de una poderosa coalición de barones y eclesiásticos contra Juan sin Tierra, que concluyó con la Carta Magna de 1215. Por ella se estableció que ningún tributo podía ser creado sin consentimiento del Consejo del Reino: El tributo requiere de la ley para evitar excesos del poder soberano9.

El Estado Moderno nacido bajo el signo del absolutismo, fortaleció el poder real para establecer tributos lo que aumentó las protestas, que condujeron al Bill de Derechos de Lores y Comunes de 1689 en Inglaterra, la Guerra de Independencia de los Estados Unidos de Norte América y la Creación de las Provincias Unidas del Río de la Plata de 1776 y la Revolución Francesa de 1789, por citar algunos hitos (Linares Quintana, S., 1956, p. 309). Es en la Modernidad donde se manifiestan más fuertemente, las dificultades en la relación entre la Economía y el Estado (López Varela, M., 1925, p., 6). El Mercantilismo es una muestra de ello en su búsqueda de la balanza comercial favorable ${ }^{10}$ (Rodríguez, C., 2008, p. 243) y de los derechos de exportación e importación, que son impuestos al consumo. La Fisiocracia ensalzó el orden natural y procuró remover las trabas estatales a la producción, entre ellas los tributos. La escuela clásica analizó los más importantes impuestos de su tiempo en Inglaterra, su traslación e incidencia. Los justificaban con carácter restringido por una relación de intercambio con el Estado Gendarme ${ }^{11}$ que regulaba la vida de las personas mediante los contratos.

\footnotetext{
${ }^{8}$ Como el ultra tribute creado por Catón el Censor para contrarrestar la decadencia de las costumbres, que imponía un gravamen mayor a los bienes suntuarios.

${ }^{9}$ Antecedente del principio de reserva de ley - artículo 19 C.N.

${ }^{10}$ Las exportaciones debían superar a las importaciones, en una concepción donde el dinero era más importante que los bienes y el gobierno intervenía en todas las actividades económicas.

${ }^{11}$ Para este concepto, el Estado no interviene en la vida económica salvo para asegurar las funciones básicas. Protege la libertad personal, la libre competencia y la propiedad privada.
} 
En la Edad Contemporánea hubo más conciencia social que durante la Modernidad debido a que el criterio histórico se constituyó en criterio de Verdad, desplazando la confianza iluminista en la Razón (Ciuro Caldani, M., 2003, p. 94). La Escuela Histórica representada principalmente por Savigny influye significativamente al sostener que todo el fenómeno jurídico es derecho público, en cuanto expresa la voluntad colectiva y la Economía de Mercado y sienta las bases de nuevas instituciones protectoras de la propiedad y del capital ${ }^{12}$ (Sagués, N., 2004, p. 52). De este contexto derivan corrientes tanto de derecha como de izquierda; y todo el siglo XX es una muestra de ello. El concepto y la importancia de los tributos no permanecen ajenos a ambas posiciones.

En la Posmodernidad las relaciones de producción superaron las fronteras de los Estados Nacionales, dando nacimiento a las nuevas dimensiones de la globalización (Touraine, A., 2006, p. 33). El capital se concentró siguiendo las consideraciones de Marx acerca de la plusvalía (Roll, E., 1973, P. 245) y el número de personas marginadas y excluidas inició el debate acerca de una nueva tensión, esta vez entre democracia y desarrollo (Sartori, G., 2005, p. 257). Los modelos elaborados para superar la pobreza y la exclusión, tanto por los organismos supra nacionales como por los países individualmente, tienen a los tributos como un instrumento primordial de sus reformas.

En síntesis, la historia de nuestras sociedades muestra que alzamientos, revoluciones, guerras, conflictos sociales, separaciones y reconciliaciones, han tenido al tributo como una de sus causas, cuando no la principal.

\subsection{EL CONTEXTO ESPACIAL: EL DERECHO TRIBUTARIO COMPARADO}

En cuanto al ámbito espacial, hay dos escenarios de aplicación: el internacional especialmente marcado por el derecho internacional público y privado; y el nacional, donde juegan las normas de derecho constitucional, público provincial y municipal.

En el ámbito internacional el fenómeno de la globalización y sus consecuencias sobre las barreras aduaneras, amplió los casos de competencia fiscal nociva entre los países ${ }^{13}$, los precios de transferencia ${ }^{14}$ entre las empresas vinculadas y el aumento de paraísos fiscales ${ }^{15}$, entre otras distorsiones. El avance de estos hechos llevó al desarrollo de una nueva rama, el "derecho tributario de la integración" o "derecho fiscal comunitario", que para algunos autores

\footnotetext{
${ }^{12}$ El constitucionalismo social garantiza la libertad, la libre contratación y la propiedad como bases del sistema económico. ${ }^{13}$ Es el caso de la doble o múltiple imposición internacional o imposición duplicada, que se da cuando el mismo contribuyente es gravado dos o más veces por el mismo hecho imponible, en el mismo periodo y por dos o más Estados. Se resuelven mediante convenios con el fin de establecer relaciones tributarias armónicas.

${ }^{14}$ Ocupan un lugar muy importante entre las distorsiones fiscales. Son los que fijan los grupos económicos o empresas vinculadas, favorables a su interés y distintos a los que fijan para competir las empresas independientes, actuando en circunstancias similares. En general se usan como un mecanismo de reducción del total de tributos del grupo económico actuante.

${ }^{15}$ Su concepto se comprende mejor de su traducción directa del inglés: (tax avens) refugios fiscales. Son países con baja o nula fiscalidad, que otorgan privilegios tributarios especiales derivados de combinar disposiciones internas y tratados. La base del sistema está en el riguroso secreto bancario y en la falta de control sobre el cambio de moneda.
} 
se inició junto con la Comunidad Económica Europea (Villegas, H., 2003, p. 653). Y luego se agregaron otros fenómenos de integración como el Mercosur. En este ámbito, la armonización fiscal - aún incipiente - es clave para el desarrollo.

En el ámbito nacional, el régimen federal de gobierno produce no pocas dificultades al momento de delimitar los poderes tributarios para evitar la doble y múltiple imposición, derivada de la coexistencia de poderes tributarios asignados constitucionalmente a la Nación, las Provincias y los Municipios. Una alternativa para hacer frente al problema es la de coordinar el ejercicio del poder de imposición mediante convenios ${ }^{16}$.

\subsection{EL CONTEXTO MATERIAL: EL DERECHO TRIBUTARIO Y LAS RAMAS DEL MUNDO JURÍDICO}

El aspecto material, es el contenido del derecho tributario, su singularidad o autonomía como rama del derecho en general (Jarach, D., 1998, p. 99), del derecho público en particular y en relación a las otras ramas del mundo jurídico. Contiene a la relación jurídica tributaria, sujetos, hecho y base imponibles (Saccone, M., 2002, p. 79). El contenido material está impregnado de particularidades en las tres dimensiones: sociológica, normológica y dikelógica; así como de perspectivas doctrinarias - tradicionales y nuevas - . La materialidad - autonomía - puede ser primaria o secundaria, ambas se conectan e interrelacionan.

La autonomía primaria tiene aspectos particularmente debatidos, como las fuentes, el funcionamiento de las normas y la profesionalidad, entre otros.

Con respecto a las fuentes: la admisibilidad/inadmisibilidad de la delegación legislativa en materia tributaria.

Con respecto al funcionamiento de las normas: la legitimidad/ilegitimidad del ejercicio del poder reglamentario para crear tributos y/o interpretar normas.

Con respecto a la profesionalidad: la participación interdisciplinar y la delimitación de responsabilidades, en principio de abogados y contadores, aunque otras profesiones también tendrán participación cada vez mayor si se tiene en cuenta que el substrato de la tributación es una manifestación de riqueza (renta, patrimonio o consumo) vinculada directa o indirectamente a una actividad económica.

La autonomía primaria vincula al derecho tributario con otras ramas del derecho como el derecho constitucional, administrativo y penal, por citar las relaciones tradicionales más notorias; pero también hay vínculos con otras ramas nuevas como el derecho ambiental ${ }^{17}$.

\footnotetext{
${ }^{16}$ En la Argentina, el régimen de Coparticipación Federal incorporado a la Carta Constitucional con la reforma de 1994, que sin embargo no tiene cumplimiento por no haberse sancionado la ley convenio. Rigen en su lugar un conjunto de pactos fiscales con distintos criterios de reparto, que afectan su equidad.

${ }^{17}$ Los tributos ambientales constituyen incentivos para tomar decisiones protectoras del ambiente y por lo tanto tienen finalidad extra fiscal. Pueden ser utilizados por el Estado para alentar/desalentar actividades y conductas. Son formas novedosas de intervención pública en los mercados y tienden a producir impacto en la calidad de vida de la población.
} 
Con respecto a la autonomía secundaria merece particular tratamiento el aspecto educativo. En lo curricular, el derecho tributario se ha separado no hace mucho del derecho financiero en algunas Facultades de derecho, mientras que en la mayoría ${ }^{18}$ aun forma parte del currículo de aquél. En lo pedagógico la educación tributaria amplió notablemente sus fronteras y hoy se ha extendido más allá de los muros de la educación formal, con el objetivo de fortalecer la conciencia ciudadana en el deber de contribuir al sostenimiento del Estado ${ }^{19}$.

\subsection{LAS TEORÍAS JURÍDICAS TRIBUTARIAS}

En virtud de los hechos y de sus contextos, las teorías jurídicas construyen un concepto de tributo, con el propósito de brindar respuestas a los problemas concretos del Derecho Tributario. Por un lado y en un sentido más general, las positivistas afirman que el tributo es lo que las normas dicen que es; y por el otro, las jus naturalistas lo entienden como un derecho/ deber natural referente de una manifestación de riqueza - renta, patrimonio o consumo - que proviene de la propiedad privada (Villegas, H., 2003, p. 59).

Este trabajo tiene como propósito, superando ambas posiciones, analizar el tributo como un objeto jurídico integral, desde la perspectiva que ofrece la teoría trialista del Mundo Jurídico ${ }^{20}$.

\section{EL TRIBUTO EN EL MUNDO JURÍDICO}

\subsection{DIMENSIÓN SOCIAL}

Esta dimensión abarca adjudicaciones de lo que favorece (potencia) o perjudica (impotencia) al ser, es decir, a la vida. Se trata de adjudicaciones de vida, distribuciones que se producen por la naturaleza, las influencias humanas difusas o el azar; y repartos que provienen de las conductas de seres humanos determinables que como tales, actúan en libertad, y siempre teniendo en cuenta que el ejercicio pleno de la libertad no es absoluto sino que se perfila según un juego contrastante de permisos y restricciones (Díaz, E., 2005, p. 77).

El tributo se produce normalmente por repartos y tiene especial significado el grado de oportunidad en que se realizan estos repartos, es decir la situación concreta en que se decide el tributo ${ }^{21}$.

\footnotetext{
${ }^{18}$ Entre ellas la Facultad de Derecho de la Universidad Nacional del Nordeste (UNNE).

${ }^{19}$ En este sentido participamos en la Universidad Nacional del Nordeste de programas sobre educación tributaria en convenio con los Municipios, voluntariado y en actividades de extensión.

${ }^{20}$ Elaborada por el Profesor Werner Goldschmidt en el año 1960 y consultada en su última versión publicada en 1987. También en su continuador y principal referente actual, el profesor rosarino Miguel Ángel Ciuro Caldani.

${ }^{21}$ Éste es el aspecto dinámico de los repartos y está en relación con los valores de convivencia que la sociedad tiene en mira.
} 
Para comprender el significado del reparto es necesario distinguir repartidores, recipiendarios, objeto, forma y razones. Los repartidores son las personas que conducen - conductores -. Los recipiendarios son los receptores de potencia o impotencia (el objeto) que los favorecen o perjudican y que provienen de los repartidores. La forma es el camino elegido previamente para efectuar el reparto. Las razones son: los móviles del repartidor, las razones alegadas y las que la sociedad considera fundamento del reparto.

El repartidor o conductor en un tributo es primordialmente el legislador. Desde sus orígenes, la tributación presentó una tensión permanente entre el ejercicio del poder soberano y la libertad individual, hasta que alcanzó su legitimidad mediante la creación parlamentaria. Es por eso que los conductores ${ }^{22}$ deben tener especialmente en cuenta los límites necesarios de reparto, para no caer en el fracaso. El aporte interdisciplinar cobra gran importancia para evaluar la complejidad de los hechos ${ }^{23}$. Ciencias tradicionales como la Sociología y otras más nuevas como la Bioética, pueden contribuir para evaluar tipos y comportamientos de los actores involucrados.

Los recipiendarios principales de los tributos, aquellos beneficiados o perjudicados con las potencias o impotencias, son las personas físicas, jurídicas y sucesiones indivisas ${ }^{24}$ que quedan comprendidas en el hecho imponible y reciben el nombre genérico de contribuyentes ${ }^{25}$ (Gómez, T., y Folco, C., 2007, p. 69). A estos hay que agregar los recipiendarios indirectos, que son aquellos que reciben el reparto extra fiscal; y aun toda la sociedad, por lo que podría pensarse en recipiendarios tributarios universales. El tributo es un instrumento de política fiscal que puede coadyuvar a construir sociedades más inclusivas ${ }^{26}$. No se trata de que todos deban tributar sino que nadie sea eximido de hacerlo por privilegios o intereses personales o de clase ${ }^{27}$. En este sentido, el ámbito de aplicación de los recipiendarios debe proyectarse al conjunto de la sociedad, porque el tributo es una de las formas de distribución de la riqueza ${ }^{28}$.

\footnotetext{
${ }^{22}$ En el reparto de los tributos pueden participar además, el administrador y el juez.

${ }^{23}$ El hecho imponible, denominación que debemos a Dino Jarach, ha sido objeto desde su construcción, de análisis económicos y jurídicos, al que más recientemente se agregaron los sociológicos. Por ello lo consideramos una interesante plataforma de despliegue de la teoría trialista del mundo jurídico.

${ }^{24}$ Para el derecho privado, las sucesiones indivisas son objeto de derecho, en cuanto constituyen un régimen particular de propiedad y administración sobre una universalidad jurídica especial, emergente del fallecimiento del titular, de carácter transitorio y cuya finalidad es liquidar el activo y pasivo que la componen para la posterior distribución entre sus herederos. Sin embargo para el derecho tributario son sujeto de derecho, por aplicación expresa de la Ley 11683 - de Procedimiento tributario, art. $5^{`}$ - y la Ley 20628 - de Impuesto a las Ganancias, art 33 - que las considera contribuyentes por las ganancias que obtengan hasta la declaratoria de herederos.

${ }^{25}$ Las leyes tributarias no definen al contribuyente. La doctrina se refiere a él como "el destinatario legal del tributo, aquel a quien tuvo en cuenta el legislador al momento de construir el hecho imponible" .La denominación tiene raíz constitucional (art. 4 C.N.)

${ }^{26}$ En el reparto de los tributos pueden participar además, el administrador y el juez.

${ }^{27}$ El hecho imponible, denominación que debemos a Dino Jarach, ha sido objeto desde su construcción, de análisis económicos y jurídicos, al que más recientemente se agregaron los sociológicos. Por ello lo consideramos una interesante plataforma de despliegue de la teoría trialista del mundo jurídico.

${ }^{28}$ Para el derecho privado, las sucesiones indivisas son objeto de derecho, en cuanto constituyen un régimen particular de propiedad y administración sobre una universalidad jurídica especial, emergente del fallecimiento del titular, de carácter transitorio y cuya finalidad es liquidar el activo y pasivo que la componen para la posterior distribución entre sus herederos. Sin embargo para el derecho tributario son sujeto de derecho, por aplicación expresa de la Ley 11683 - de Procedimiento tributario, art. $5^{`}$ - y la Ley 20628 - de Impuesto a las Ganancias, art 33 - que las considera contribuyentes por las ganancias que obtengan hasta la declaratoria de herederos.
} 
La tributación genera también un problema de recepción. Dentro del régimen tributario argentino hay dos ámbitos bien definidos. Los contribuyentes generales y los pequeños contribuyentes, erróneamente denominados monotributistas dado que el gravamen no refiere a un solo tributo sino a un conjunto de ellos: ganancias, valor agregado y aportes a la seguridad social (Ayala Rojas, D., y Baez, J., 2001, p. 73).

Los contribuyentes generales son los recipiendarios principales de los tributos (y ya mencionados en los párrafos anteriores) mientras que los pequeños contribuyentes constituyen un grupo especial de recipiendarios que tributan solamente Ganancias, IVA y Seguridad Social bajo la forma de una suma fija y siempre y cuando cumplan los parámetros de ingresos, consumos eléctricos y superficie ocupada establecidos ${ }^{29}$. Las ventajas que ofrece el régimen simplificado atrae a los contribuyentes generales quienes buscan - a veces forzadamente - no superar los parámetros de exigencia. Merece especial atención, la situación de las sociedades comerciales irregulares y de hecho ${ }^{30}$ en atención a los límites necesarios de los repartos.

También revisten interés los espacios correspondientes a los recipiendarios profesionales que intervienen en la tributación - abogados, contadores, escribanos - con relación a su participación y honorarios.

Los objetos (potencias o impotencias) que integran los repartos tributarios, remiten a las manifestaciones de riqueza, patrimonio y consumo de los contribuyentes por ser consideradas por el legislador como exteriorización de su capacidad contributiva. En la renta y el patrimonio la manifestación se produce en forma directa o inmediata, mientras que en el consumo es indirecta o mediata. Pueden observarse mejor estos rasgos en los impuestos más conocidos: Sobre las Ganancias y sobre los Bienes Personales (impuestos directos a la renta y al patrimonio, respectivamente) y sobre el Valor Agregado (impuesto indirecto). Un aspecto a considerar es el de fortaleza/debilidad de los recipiendarios en las manifestaciones directas e indirectas de riqueza (posibilidad de traslación del impuesto).

La forma, entendida como el camino para llegar al reparto, surge de la ley. No hay tributo sin ley previa que lo establezca. El reparto debe surgir del acuerdo parlamentario y en ese sentido como producto de la cooperación, es autónomo. Pero en algunas situaciones, cada vez más frecuentes en regímenes tributarios como el nuestro, el reparto se hace por la fuerza o el poder y entonces es autoritario. Cuando los repartos son autoritarios el limite necesario ${ }^{31}$ es mayor y más frecuente que en los autónomos. Hay que prestarles atención para que el reparto no fracase.

El tributo legislativamente creado debe transformarse en tributo fiscalmente percibido y eso da lugar al procedimiento tributario. Gestión, inspección y recaudación ${ }^{32}$ (Pérez de Ayala,

\footnotetext{
${ }^{29}$ Las leyes tributarias no definen al contribuyente. La doctrina se refiere a él como "el destinatario legal del tributo, aquel a quien tuvo en cuenta el legislador al momento de construir el hecho imponible". La denominación tiene raíz constitucional (art. 4 C.N.).

${ }^{30}$ En concordancia con el programa constitucional argentino de que "la igualdad es la base de los impuestos y cargas publicas" art. 16 C.N.

${ }^{31}$ Cuando hay límites necesarios, se quiere pero no se puede. El límite esta impuesto por la misma naturaleza de las cosas.

${ }^{32}$ Su contenido refiere en especial, a las normas que el Fisco utiliza para la determinación de la obligación tributaria.
} 
J., y Pérez de Ayala, M., 2013, p. 153).

Con respecto a las razones hay que distinguir: los móviles del repartidor, que se justifican por el deseo del legislador - juicios de valor - de organizar la sociedad mediante una distribución equitativa de la renta. Es un reparto que proviene de una planificación de gobierno que establece máximos repartidores y máximos criterios. También hay que considerar las razones que alega y las razones que tiene la sociedad para justificar el reparto.

\subsection{DIMENSIÓN NORMATIVA}

Es la dimensión de la validez jurídica y apunta más a las partes que al conjunto. Para el trialismo, la norma es la captación lógica y promisoria ${ }^{33}$ de un reparto proyectado que procura realizarse. Para ello es necesario que la norma funcione.

En la construcción de la norma se advierte por un lado, su antecedente como captación lógica de la realidad social a reglar; y por el otro, la consecuencia jurídica o captación lógica de la regla. Esta estructura de la norma que podemos llamar bimembre, tiene sus caracteres positivos y negativos. Los primeros son los que se advierten en su funcionamiento y los segundos los que no aparecen en él. Hay caracteres negativos que son especialmente trascendentes en la norma tributaria. Por ejemplo, un carácter negativo en los antecedentes es el rechazo del fraude a la ley que se da cuando se utilizan negocios jurídicos engañosos para eludir el tributo ${ }^{34}$. En las consecuencias jurídicas, el carácter negativo se da con el rechazo de procedimientos de la Administración tributaria que afecten el debido proceso ${ }^{35}$.

Con relación a las fuentes, los tributos tienen su fuente mas importante en la ley, ya sea entendida como constitución en sentido formal, tratados internacionales, sentencias etc. Por tratarse de fuentes formales son relatos de repartos - abstractos e históricos - efectuados por los mismos repartidores. Por el carácter formal de sus fuentes, el tributo tiende a ser rígido es decir, con poco margen para las reformas, las que no pueden ir más allá de las fuentes. Sin embargo, los tributos son muy sensibles a los cambios de la realidad social y por lo tanto, elásticos.

La norma concreta su funcionamiento real ${ }^{36}$ mediante diversas operaciones: reconocimiento, interpretación, determinación, elaboración, argumentación, aplicación y síntesis. Este proceso es muy importante porque hace “operativos" los repartos proyectados y los convierte en repartos realizados.

La fase de reconocimiento culmina con la validez o nulidad de la norma tributaria. $\mathrm{Su}$ rechazo puede producirse por diversas razones, pero es muy común en materia tributaria que

\footnotetext{
$\overline{33}$ Las normas son promisorias en cuanto aseveran que lo proyectado "será"; revelando de este modo una mayor integración con la realidad social.

${ }^{34}$ Se denomina también infracción encubierta porque quien la realiza, no produce el hecho imponible contemplado en la norma pero llega al mismo resultado económico que la ley se proponía gravar.

${ }^{35}$ Por ejemplo, la no aplicabilidad de una sanción administrativa cuando preexiste sentencia penal absolutoria. La garantía constitucional prohíbe la doble o múltiple sanción penal.
} 
lo sea por derogación o por tacha de inconstitucionalidad.

La fase de interpretación tiene que ver con la intención del legislador o de quienes hacen operativa la norma tributaria. Es particularmente relevante la constante tensión entre legislador, administrador y juez. La doctrina ha elaborado principios tributarios que son derivados de las fuentes formales y que constituyen mandatos interpretativos óptimos.

La fase de determinación puede comprender dos situaciones: que la norma este incompleta y por lo tanto requiera su integración por otra norma que la precise o reglamente; o que la norma tributaria sustantiva por ser genérica, deba incorporar un procedimiento que individualice al sujeto comprendido en el hecho imponible y su cuantificación.

Cuando no existen normas se hace necesario incorporar otra fase/tarea: la elaboración para superar la carencia e integrar el sistema.

La fase de la argumentación tiene especial significado por su relación con la justificación del tributo, su generalidad y su cuantificación. La utilización de exenciones, olvidos fiscales, bloqueos y otros beneficios requieren de una aceptación por el auditorio.

La fase de la aplicación comprende el encuadramiento del hecho en la norma tributaria - subsunción - y la realización de la consecuencia jurídica prevista, la concreción del reparto proyectado. Es aquí donde la realidad se modifica.

La fase de síntesis es la culminación del proceso. Implica la búsqueda de la verdad que va a surgir de todos los proyectos de reparto que están en juego, es decir de la yuxtaposición de intereses.

La norma tributaria integra el sistema jurídico general mediante un sub ordenamiento ${ }^{37}$ que debe conectarse con los demás de manera coherente. Así por ejemplo, las disposiciones sobre domicilio fiscal, prescripción, notificaciones, etc.

\subsection{DIMENSIÓN VALORATIVA (DIKELÓGICA)}

La dimensión valorativa - o dikelógica ${ }^{38}$ en la expresión de Werner Godschmidt - del objeto jurídico, incluye valores reunidos en una complejidad cuyo máximo exponente es la justicia, sea que ésta se considere natural o construida ${ }^{39}$. Junto con ella conviven otros valores

\footnotetext{
$\overline{{ }^{36} \text { Además de su funcionamiento real, la norma tiene un funcionamiento conjetural que se refiere a lo que la sociedad piensa de lo }}$ que iría a suceder si un caso fuera sometido al funcionamiento real.

${ }^{37}$ La norma que rige el régimen tributario en jurisdicción nacional es la Ley 11.683 de contenido bastante amplio pues abarca disposiciones de derecho sustantivo como las calidades de los sujetos pasivos; y de derecho formal, como la determinación de facultades del poder administrador; de derecho procesal, como la descripción del procedimiento ante el Tribunal Fiscal; de derecho penal, como la tipificación de ilícitos y sanciones. En ese sentido, se dice que los tributos tienen codificación limitada.

${ }^{38}$ Diké o Dicea, es en la mitología griega una de las Horas y representa a la justicia. Su equivalente en la mitología romana es lustitia. ${ }^{39}$ Para Goldschmidt la justicia es natural y objetiva; para Ciuro Caldani puede ser construida mediante el consenso. En cualquier caso es necesario el acuerdo sobre un principio fundamental - principio supremo - a partir del cual valorar el deber ser y el ser en cuestión; sin cuya referencia común no hay rigor metodológico posible. Goldschmidt sostuvo que el principio supremo es asegurar a cada cual una esfera de libertad dentro de la que sea capaz de desarrollar su personalidad, de convertirse de individuo en persona, de personalizarse.
} 
como la utilidad y la solidaridad que en materia tributaria son establecidos actualmente por el legislador. Decimos actualmente, porque en su desarrollo histórico los tributos fueron resultado del juego de otros valores: la fuerza, el credo, el interés del príncipe, etc.

Las clases de justicia y las relaciones entre valores integran lo que el Profesor Golschmidt, denominó Método Dikelógico. Éste adquiere significativa importancia porque considera que la malla social se nutre de una base común o acuerdos sobre la justicia. Si entendemos al tributo como una construcción cultural de repartos, resulta crucial conocer los modos de pensar ese valor y su relación con un principio supremo de justicia.

Los valores utilidad y solidaridad han puesto el acento sobre los tributos en relación con sus fines. Por un lado, si se considera que ellos son exclusivamente fiscales como sostiene la vertiente anglosajona (escuela clásica) el valor primordial es la utilidad. Por el otro, si se considera que los fines del tributo deben ir más allá de la recaudación y permitir una distribución de la renta - escuelas keynesianas - entre todos los miembros de la sociedad, el valor predominante es el de solidaridad. Sin embargo hay que aclarar que el capitalismo ha llevado al extremo la noción de utilidad, lo que se hizo evidente en la posmodernidad con el auge de algunas escuelas como la del Análisis Económico del Derecho y sus aportes sobre la eficiencia.

Otra vertiente representada por la filosofía critica, tanto de autores alemanes ${ }^{40}$ como franceses ${ }^{41}$, cuestiona la importancia dada al valor utilidad y concluye que el consumo hace a los ciudadanos tremendamente desiguales ${ }^{42}$ (Bauman, Z., 2007, p. 18).

En base a la distinción aristotélica sobre clases de justicia y teniendo en cuenta los repartos aislados (a) y el régimen (b) ${ }^{43}$; se puede decir que el tributo tiene rasgos predominantes de:

(a)

Justicia consensual, donde los repartidores buscarán acuerdos.

Justicia con consideración, donde los recipiendarios serán tenidos en cuenta por su condición de personas y no por sus roles.

Justicia asimétrica, donde la comparación de potencias/impotencias en relación al objeto será difícil.

Justicia dialogal, donde en lo formal habrán varias razones de justicia.

Justicia conmutativa, donde las razones requerirán contraprestaciones.

(b)

Justicia gubernamental, donde los repartidores adjudicarán el todo.

\footnotetext{
${ }^{40}$ Como Jurgen Habermas y sus ideas sobre el Estado democrático de derecho en términos de acción comunicativa, que sirve para entender al hombre como sujeto libre.

${ }^{41}$ Como Michel Foucault y su análisis sobre el discurso del poder.

${ }^{42}$ La desigualdad como producto del consumo está planteada también por la sociología contemporánea. Explica que el examen que uno debe aprobar para acceder a los tan codiciados premios sociales exige reciclarnos bajo la forma de bienes de cambio, como productos capaces de captar la atención, atraer clientes y generar demanda.

${ }^{43}$ Es decir, como conjunto de repartos.
} 
Justicia integral, donde los recipiendarios integrarán el todo.

Justicia de participación, donde los objetos serán compartidos.

Justicia relativa, con igualdad de trato.

Justicia general, donde las razones atenderán al bien común.

Por ser una categoría pantónoma, la justicia es siempre compleja. En consecuencia puede integrarse por distintos caminos aun dentro de una misma clasificación. Todas las formas se necesitan mutuamente y en definitiva, siempre hay relatividad en la justicia que desagregamos para resolver un caso (y que a su vez volvemos a unir y separar) con relación a la justicia en abstracto o general.

\section{CONCLUSIÓN}

Pensar al tributo desde la complejidad, es asunto de antigua data en la doctrina del derecho tributario (González García E., y Lejeune, E., 2000, p. 103). Basta con recordar que una de las polémicas más acuciantes se produjo en torno de la interpretación del significado económico de las normas tributarias o de la realidad económica; criterio que si bien se concretó como derecho positivo en la Ley de Procedimiento Tributario Nacional ${ }^{44}$ es aún muy discutido por quienes rechazan toda interpretación no derivada estrictamente de la norma ${ }^{45}$. Como consecuencia de ello, economistas y juristas muchas veces parecen enfocar objetos distintos cuando en realidad se refieren a uno solo - el tributo - aunque en distintas dimensiones.

Por eso sostenemos que el reconocimiento integrado ${ }^{46}$ (Alexy, R., 2008) y no yuxtapuesto de los aspectos sociológicos, normativos y axiológicos del Tributo, objeto central de la disciplina que nos ocupa, facilita con su flexibilidad ${ }^{47}$ la producción de más Derecho Tributario ${ }^{48}$.

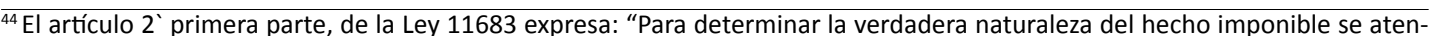
derá a los actos, situaciones y relaciones económicas que efectivamente realicen, persigan o establezcan los contribuyentes...; que se relaciona con el articulo 1 ` primera parte:" En la interpretación de las disposiciones de esta ley o de las leyes impositivas sujetas a su régimen, se atenderá al fin de las mismas y a su significación económica"... El criterio es desarrollado por la doctrina germano italiana a partir de los trabajos de Enno Becker que culminan con la redacción de la Ordenanza Tributaria Alemana. Luego en Argentina, lo profundiza Dino Jarach que lo recibe de la Escuela de Pavía y de su maestro Griziotti.

${ }^{45} \mathrm{Sin}$ embargo al menos puede reconocerse que el criterio de la realidad económica tiene el mérito de haber removido el positivismo tanto formalista como empírico, que regía la ciencia jurídica a fines del siglo XIX

${ }^{46}$ La jus filosofía alexyana aporta a la complejidad del derecho con sentido integral al relacionar como sus componentes a la promulgación adecuada, la eficacia social (su dimensión real) y la corrección moral (su dimensión ideal); dentro de lo que denomina su concepción no positivista del derecho.

${ }^{47}$ El rasgo de flexibilidad que ofrece el trialismo, nos parece que constituye una importante colaboración para aliviar la tensión entre poder soberano y libertad individual; tensión que - como señalamos al principio - caracteriza ab initio a los tributos.

${ }^{48}$ La cursiva pretende hacer notar la posibilidad de producir nuevos y diferentes desarrollos, derivados del esclarecimiento reciproco que se da entre las partes y el todo.
} 


\section{REFERENCIAS BIBLIOGRÁFICAS}

Alexy R. (2008) La doble naturaleza del derecho. Conferencia al recibir el título de Doctor H. C. de la Universidad Nacional de Tucumán. República Argentina.

Alexy R. (2004) Teoría del discurso y derechos humanos. Bogotá. Universidad Externado de Colombia.

Atkinson A. y Stiglitz J. (1988) Lecciones sobre Economía Política. Madrid. Instituto de Estudios Fiscales.

Ayala Rojas D. y Baez J. (2001) Algunas herramientas de política tributaria. El caso Argentino. (pp. 73-75). En XXIII Congreso Latinoamericano de Sociología. Antigua, Guatemala: Asociación Latinoamericana de Sociología.

Bauman Z. (2007) Vida de consumo. Buenos Aires. Fondo de Cultura Económica.

Bauman Z. (2007) En busca de la política. Buenos Aires. Fondo de Cultura económica.

Bulit Goñi E. (2002) Derecho Tributario Provincial y Municipal. Buenos Aires. Ad Hoc.

Campagnale N. (2000) El impacto de la tributación sobre las operaciones internacionales. Buenos Aires. La Ley.

Ciuro Caldani M A. (2008) Metodología Jurídica y Lecciones de Historia de la Filosofía del Derecho. Rosario. Zeus.

Ciuro Caldani M. A. (2007) Metodología Dikelógica. Rosario. Fundación para las investigaciones jurídicas.

Ciuro Caldani M.A. (2003) Lecciones de Filosofía de Derecho Privado. Rosario. Fundación para las investigaciones jurídicas.

Corti H. (2007) Derecho Constitucional Presupuestario. Buenos Aires. Lexis Nexis.

Dalla Vía A. (1999) Derecho Constitucional Económico. Buenos Aires. Abeledo Perrot. 
Damarco J. (2010) Tratado Jurisprudencial y Doctrinario de Derecho Tributario. Buenos Aires. La Ley.

Falcón y Tella M. (2014) La Justicia como mérito. Madrid. Marcial Pons.

Foucault M. (2005) Las palabras y las cosas. Buenos Aires. Siglo XXI.

García Belsunce H. (2003) Tratado de Tributación. Buenos Aires. Astrea.

Giuliani Fonrouge C., Navarrine S. y Asorey S. (2004) Derecho Financiero. Buenos Aires. La Ley.

Gómez T. y Folco C. (2008) Procedimiento Tributario. Buenos Aires. La Ley.

González E. y Lejeune E. (2000) Derecho Tributario. Salamanca. Plaza Universitaria.

Gonzalez García E. (1997) La interpretación de las normas tributarias. Salamanca. Aranzadi.

Guestrin S. (2004) Fundamentos para un nuevo Análisis Económico del Derecho. Buenos Aires. Ábaco.

Habermas J. (2005) Facticidad y validez. Madrid. Trotta.

Hensel A. (2004) Derecho Tributario. Rosario. Nova Tesis.

Jarach D. (2004) El Hecho Imponible. Buenos Aires. Abeledo Perrot.

Jarach D. (1999) Finanzas Públicas y Derecho Tributario. Buenos Aires. Abeledo Perrot.

Lascano M. (2002) Impuestos. Doctrinas fundamentales. Buenos Aires. La Ley.

Massini Correas C. (2005) Filosofía del Derecho. La Justicia. Buenos Aires. Lexis Nexis.

Pérez de Ayala J. y Pérez de Ayala Berrecil M. (2013) Fundamentos de Derecho Tributario. Madrid. Dykinson.

Sabsay D. (2005) Derecho Constitucional. Buenos Aires. La Ley. 
Saccone M. (2002) Manual de Derecho Tributario. Buenos Aires. La Ley.

Sartori G. (2005) Elementos de Teoría Política. Madrid. Alianza.

Solá J. (2004) Constitución y Economía. Buenos Aires. Lexis Nexis.

Soler O. (2005) Derecho Tributario. Buenos Aires. La Ley.

Stiglitz J. (2002) El malestar de la globalización. Buenos Aires. Taurus.

Teijeiro G. (2002) Estudios sobre la aplicación espacial de la ley tributaria. Buenos Aires. La Ley.

Touraine A. (2006) Un nuevo paradigma para comprender el mundo de hoy. Buenos Aires. Paidós.

Villegas H. (2003) Curso de Finanzas, Derecho Financiero y Tributario. Buenos Aires. Astrea.

\section{CURRÍCULUM VITAE}

\section{Dora Esther Ayala Rojas}

Doctora en Derecho (Universidad Nacional de Rosario, 2012). Especialista en Derecho Tributario (Universidad Nacional del Litoral, 2002). Especialista en Docencia Universitaria (Universidad Nacional del Nordeste, 2002). Título obtenido en el exterior: Especialista en Derecho Tributario (Universidad de Salamanca, 2003). Cargos académicos y científicos actuales: Profesora Titular Regular de Derecho Financiero y Tributario. Profesora Adjunta Regular de Economía Política c/ Régimen Mayor Dedicación Investigadora Categorizada Nivel III. Directora de Proyectos de Investigación acreditados de la UNNE. Miembro Activo de la Asociación Argentina de Estudios Fiscales. Con Jueza de Jurisdicción de la Excma. Cámara Federal de Apelaciones de Corrientes (Acordadas 248/12 y 317/13).

dorayala@gigared.com 